\title{
The Influence of Plasticizers on the Composition of Cement Stone Hydration Products
}

\author{
Tarakanov Oleg Vyacheslavovich ${ }^{1,}$, Belyakova Elena Aleksandrovna ${ }^{1, b^{*}}$, \\ Kalashnikov Vladimir Ivanovich ${ }^{1, c}$, Grintsova Olga Vasilyevna ${ }^{1, d}$, \\ Makridin Nikolai Ivanovich ${ }^{1, \mathrm{e}}$ \\ ${ }^{1}$ Penza State University of Architecture and Construction, \\ 28, German Titov St., Penza, The Russian Federation \\ azigk@pguas.ru, bvar_lena@mail.ru, ctechbeton@pguas.ru, dgrintsova_olga@mail.ru, \\ etechbeton@pguas.ru
}

Keywords: Plasticizers, Hydration products, Strength, Cement stone structure

\begin{abstract}
The influence of polycarboxylate super plasticizers on composition changes of silicate and aluminate cement phases is analyzed. The retarding effect of organic additives on silicate phases hydration and stabilizing effect of additives on calcium metastable hydro aluminates and ettringite is established.
\end{abstract}

\section{Introduction}

Plasticizers as substances significantly improving the properties of concrete mixes, have taken a leading place among many other additives used in concrete technology.

The purpose of using super plasticizing additives is to achieve an extremely high effect of concrete mix liquefaction, which can significantly increase the strength and durability of the products.

Plasticizing additives are surface-active substances (surfactants), their basic property is adsorption of molecules of these substances on the surface of the body and formation of a very thin mono- or bimolecular layer. The thickness of this layer is about 100000 times smaller than the average size of cement particle. Therefore the surfactant additives are used in very small doses, expressed in percent by cement weight. Surfactant is introduced at final cement grinding with addition of a plasticizer or mixing water in making concrete and mortar mixes.

Plasticizing additives, which appeared in the 30-ies of the last century, have undergone significant changes. Thus the most effective are additives on the basis of polycarboxylate, they belong to the sixth generation of plasticizers and allow to achieve high water reducing effect and get cement concrete strength (including new concrete generation) up to $200 \mathrm{MPa}$ and higher.

Complex organic-mineral additives on the basis of superplasticizers and fine fillers are widely used in concrete technology in recent years. We know that all mineral additives can be divided into two main groups in terms of their hydration activity: active and inactive. It is well known that in order to increase the activity of a binder hydration it is reasonable to use active mineral additives, binding free lime into hydro-silicate structure. The use of fine ground mineral supplements has different effect on the nature of rheological behavior of cement-filled systems. For example, some additives with mineral superplasticizers are characterized by a large diluting effect unlike cement systems. Therefore, using such additives (e.g., on the basis of dense and strong rock) we create a possibility of increasing superplasticizers efficiency and achieving large water reducing effects in cement concrete.

Another important factor in the theory and practice of using superplasticizers is a nature of their influence on the composition of the products of cement systems hydration. It is well known that in most cases organic plasticizers cause retardation of cement hydration of silicate phases and stabilize of aluminate AFm-phases rapidly formed in the early stages of hydration. However, it should be noted that the nature of the retarding effect of organic additives, as well as the nature of their influence is also different and in many ways it is determined by the structure, molecular weight and conformational composition of the additive molecules. 


\section{Results and discussion}

Modern hyperplasticizers (HP) on the basis of polycarboxylate is highly effective and can help to achieve significant plasticizing effects at lower doses than, for example, C-3 and other complex additives on its basis. In this regard, high water-reducing effects make it possible to obtain concrete with high and super high strength at rationally chosen granularmetrical composition of concrete, types, quantities and properties of mineral microfillers.

In the presence of chemical additives hydrating process is considerably complicated in cementitious systems, because of the processes of adsorption, dissolution, surface hydration, hydration in solution, the formation of crystallization nuclei which take place parallelly. It is quite natural that complex(according to conformational structure) superplasticizers molecules with negatively charged functional groups selectively adsorbed on the positively charged centers, have a negative impact on the processes of surface crystallization rate, as well as on the structure of crystallization nuclei [1]. Long side centers of hyperplasticizers molecules affect on the rate of crystallization nucleation formation in the supersaturated solution.

A positive factor of using fine microfillers in cement compositions is not only an increase of superplasticizers rheological efficiency and structure compression, but also a possibility of hydrate phases crystallization on microfiller particles, and it contributes to the formation and crystallization coatings and particles intergrowing and generally enhances the strength of the cement-filled systems.

From this point of view the nature of microfiller particles and the surface charge state are very important factors. Thus, modern superplasticizers are extremely efficient in mixed cement systems (of course taking into account the type of micro filler) and allow to achieve high water-reducing effects and, therefore, with a sharp decrease in water demand - greatly increase the strength. On the other hand, from the very beginning of water mixing complex molecules superplasticizers slow down the normal process of hydration and contribute to the formation of distorted and intensely deformed hydrate structures.

In most of experimental research of the processes of hardening filled cement compositions and concrete of new generation the effect a significant increase of strength at low W / C prevails over processes of slowing down, which is more pronounced during the formation of coagulation and early-coagulation crystallization structure. In the later period of hardening self-organizing cement systems are capable of relaxation of early stresses and damages of the structure. Obviously, to a greater extent it can apply to hydro-aluminate phases, which are rapidly formed in the early hydration period. However, small number of aluminate phases in the cement composition does not significantly impact on the final strength of cementitious compositions. At the same time superplasticizers have a negative impact on the structure of early calcium hydro-silicates (CHS). Subsequently the normal order of CHS crystallization is restored, and cement compositions get high strength. It is possible that molecules of superplasticizers embedding into hydro-silicate structure in the early stages, do not significantly affect the strength of cementitious materials in the following period.

It can be assumed that the products in the later stages of hydration may differ in their formulations with additives from formulations without additives greater in quantity than in quality.

In order to determine the nature of influence of various superplasticizers additives on the composition of hydrated phases of cement stone a series of X-ray experimental studies on diffractometer DRON-7 was carried out in the range of Bragg angles of $10-75^{\circ}$ to the shooting with measuring step $0,05^{\circ}$. The research was done on the samples aged 6 months, because by this time most of crystalline hydrate phases of cement stone are formed. The aim of research was to evaluate the influence of modern hyperplasticizers on the kinetics of hardening, the process of formation and the state of main hydration phases of cement stone.

Research of kinetics of cement stone hardening was performed with the additives of hyperplasticizers of German company BASF Construction Polymers GmbH: Melflux 4930F, Melflux 5581F, Melflux 1641F. The dosage of HP was assumed to be $0,5 \%$ by cement weight, and the procedure of plasticizer introduction was adopted in mixing water. Compositions of the samples and durability in compression test are shown in Table 1. 
Table 1. Kinetics of hardening and strength of cement stone samples.

\begin{tabular}{|c|l|c|c|c|c|c|c|}
\hline \multirow{2}{*}{$\begin{array}{c}\text { Number of } \\
\text { composition }\end{array}$} & \multicolumn{1}{|c|}{$\begin{array}{c}\text { The amount of } \\
\text { Composition }\end{array}$} & $\begin{array}{c}\text { Compressive strength, MPa } \\
\text { weight of } \\
\text { cement, [\%] }\end{array}$ & W/C & $\begin{array}{c}3 \\
\mathrm{~d} .\end{array}$ & $\begin{array}{c}14 \\
\mathrm{~d} .\end{array}$ & $\begin{array}{c}28 \\
\mathrm{~d} .\end{array}$ & $\begin{array}{c}180 \\
\mathrm{~d} .\end{array}$ \\
\hline 1 & $\begin{array}{l}\text { White Danish Aalborg } \\
\text { White CEM 52,5 } \\
\text { without additives }\end{array}$ & - & 0,4 & 45 & 46 & 49 & 51 \\
\hline 2 & $\begin{array}{l}\text { With addition of } \\
\text { Melflux 4930F }\end{array}$ & 0,5 & 0,3 & 117 & 119 & 133 & 135 \\
\hline 3 & $\begin{array}{l}\text { With the addition of } \\
\text { Melflux 5581F }\end{array}$ & 0,5 & 0,28 & 96 & 107 & 125 & 130 \\
\hline 4 & $\begin{array}{l}\text { With the addition of } \\
\text { Melflux 1641F }\end{array}$ & 0,5 & 0,29 & 92 & 98 & 103 & 107 \\
\hline
\end{tabular}

Tests on compressive strength have shown that due to a significant reduction of water content in the mixtures with HP additives the samples strength has considerably increased and it proves high efficiency of HP additives in cement systems.

Further research was carried out on X-ray samples on the most intensive reflections. It is known that one of the major products of cement stone hydration is crystallime $\mathrm{Ca}(\mathrm{OH})_{2}(\mathrm{CH})$, which is released during cement silicate phase hydrolysis, and on the whole it is a negative component of cement stone structure due to the layered structure and low strength. Therefore, in order to improve the strength of concrete and reduce the negative effect of $\mathrm{CH}$ (particularly large crystals) on the strength of cement stone active mineral additives binding $\mathrm{CH}$ into hydro-silicate structures are introduced into cement composition.

Analysis of X-ray has shown that the main feature of hydration products with HP addition is reduction of lime reflection intensities (Table 2) and an increase of intensity of reflected anhydrous silicate cement phases (Table 3).

Table 2. Intensity of lime reflections.

\begin{tabular}{|c|c|c|c|c|c|c|c|c|}
\hline \multirow{2}{*}{ Composition } & \multicolumn{7}{|c}{ The intensity $\mathrm{I}_{\max }$ at d [̊̊] } \\
\cline { 2 - 9 } & 4,93 & 3,11 & 2,63 & 1,93 & 1,79 & 1,69 & 1,485 & 1,45 \\
\hline №1 (control) & 87,3 & 23,7 & 110,5 & 38,6 & 24,8 & 23,4 & no & 10,8 \\
\hline №2 (0,5\% Melflux 4930F) & 55,2 & 49,9 & 85,6 & 19,0 & 21,6 & 11,9 & 19,2 & no \\
\hline №3 (0,5\% Melflux 5581F) & 65,4 & no & 55,3 & 25,3 & 24,0 & 15,2 & 13,6 & no \\
\hline №4 (0,5\% Melflux 1641F) & 58,2 & 20,4 & 73,6 & 15,9 & 24,4 & 18,3 & 12,5 & 13,6 \\
\hline
\end{tabular}

The results suggest that, despite rather late period of hardening, hydration processes in cement stone in the presence of HP initially slow down, and this slowing down lasts up to 6 months according to the intensities of separated crystalline hydrate phases.

In general, reduction the water content in compositions with additives allows to get greater strength in late stages of hardening, but the overall picture of dissolution kinetics and participation of silicate phases in hydration process indicate of some kind of its slowing down. This fact is very important in terms of understanding the mechanism of additives action: on the one hand they strongly dewater and on the other hand-depress the process of hydration of cement silicate phases. Some bundles lime of reflections in formulations with additives may indirectly indicate the formation of distorted and intensely deformed $\mathrm{CH}$ crystals. 
Table 3. Intensity of reflection of $\mathrm{C}_{3} \mathrm{~S}$ and $\beta-\mathrm{C}_{2} \mathrm{~S}$.

\begin{tabular}{|c|c|c|}
\hline \multirow{2}{*}{ Composition } & \multicolumn{2}{|c|}{ The intensity $\mathrm{I}_{\max }$} \\
\cline { 2 - 3 } & Alit $(\mathrm{d}=2,7761 \AA)$ & Alit $(\mathrm{d}=2,744 \AA)$ \\
\hline №1 (control) & 27,7 & 16,3 \\
\hline №2 (0,5\% Melflux 4930F) & 40,7 & 54,7 \\
\hline №3 (0,5\% Melflux 5581F) & 47,6 & 51,8 \\
\hline №4 (0,5\% Melflux 1641F) & 38,8 & 58,5 \\
\hline
\end{tabular}

In regard of hydro aluminate phases it should be noted that reflection of metastable AFm-phase $\left(\mathrm{C}_{2} \mathrm{AH}_{8}\right)$, and the most thermodynamically stable hydro aluminate phase $\mathrm{C}_{3} \mathrm{AH}_{6}$ may appear on X-ray reflection on samples with HP additives, which indicates the possibility of selective stabilization AFm-phase of calcium hydro aluminates in the presence of HP additives.

It is known [9] that AFm-phase hydro aluminates formed in the early period of hydration have a layered structure close to the structure of $\mathrm{Ca}(\mathrm{OH})_{2}$ and obtained from it during an orderly replacement of one $\mathrm{Ca}^{2+}$ ion from three on $\mathrm{Al}^{3+}$ and $\mathrm{Fe}^{3+}$. In all AFm-phases the elements are arranged in such a way that the resulting octahedral cavity, are surrounded by three water molecules from each of the adjacent layers. The layer thickness in the AFm-phase structure depends on the nature of the anion and on the quantity of interlayer water, which may vary at step dehydration from the state of maximum hydration.

From the practice of applying organic additives we know that some acceleration of hydration is due to complexing formation with aluminates and following slowing down of hydration associated with stabilization of hexagonal phase by adsorption of organic molecules on the surface of hydrates [5].

Calcium hydro sulfo aluminates one of the main elements of hydro aluminate cement stone structure. Its composition and stability determine the properties of hardening structures. One possible mechanism of accelerating the set of initial strength of cement systems with organic additives may be accelerating of ettringite formation in the early stages and its subsequent stabilization.

The authors state [5] that for columnar structures characteristic for ettringite with much water there is a possibility of organic molecules penetration inside the columnar structures and stabilization of ettringite. This coordinates with previously performed studies [9] and data on retarding of ettringite recrystallization into mono hydro sulfo aluminate calciumin the presence of organic additives.

A characteristic feature of the X-ray diffraction samples with HP addition is a sharp increase in the intensity of ettringite reflections (tab. 4) $d=2,154 \AA$ and $d=2,209 \AA$ (Fig. 2). It is obvious that the overall ettringite stabilization mechanism in the presence of organic additives is also characteristic for HP. These results suggest that in the presence of HP AFt-phase remain in the cement paste for a long period of time and the number of phases increases in the presence of additives. Thus, high content of ettringite in cement system may lead to decompaction of the structure at the change of temperature and humidity conditions of cement hardening due to ettringite recrystalization therefore stabilization of AFm-, AFt-phases in the presence of HP is a negative factor from this point.

Table 4. Intensity of ettringite reflections.

\begin{tabular}{|c|c|}
\hline Composition & The intensity I max with $\mathrm{d}=2,17 \AA$ \\
\hline №1 (control) & 14,9 \\
\hline №2 $(0,5 \%$ Melflux 4930F) & 33,3 \\
\hline №3 (0,5\% Melflux 5581F) & 28,2 \\
\hline №4 (0,5\% Melflux 1641F) & 32,4 \\
\hline
\end{tabular}



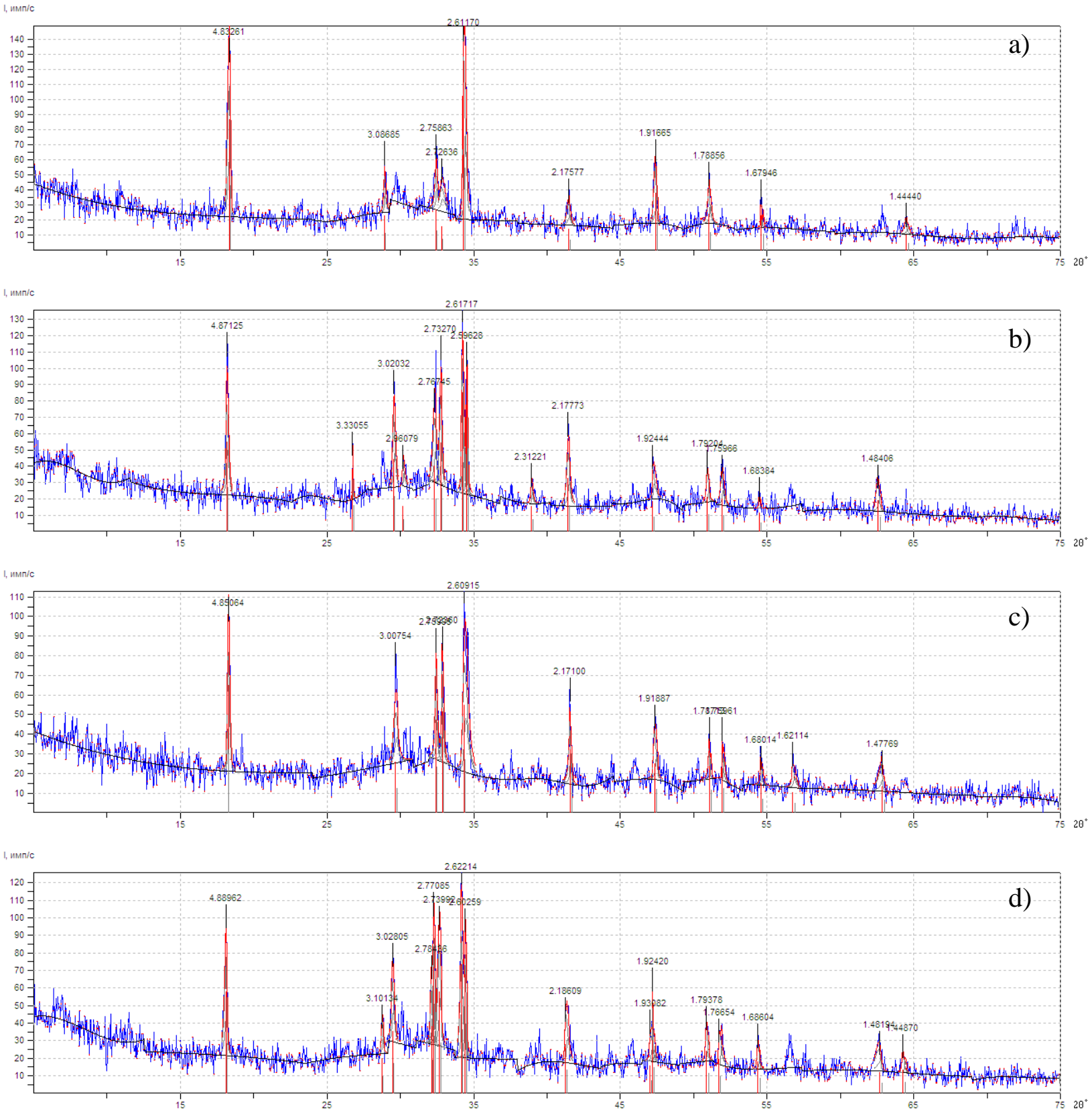

Fig. 1 Radiographs of samples: a) №1 (control); b) №2; c) №3; d) №4 (Table 1).

\section{Conclusion}

The research has shown high efficiency of Melflux additives allowing to increase the strength of cement past eat 80-100\% due to significant dewatering. However X-ray phase studies after 6 months of normal hardening showed that according to the change of intensities of hydrate and anhydrous silicate cement phases HP additives have retarding effect on the processes of hydration. It is established that in the presence of HP additives we can observe stabilization of hydro aluminate metastable AFm-phases and ettringite and retarding the processes of their recrystallization into cubic hydro aluminate structures and calcium mono hydro sulfo aluminates. The following recrystallization of AFm- and AFt-hydro aluminate phases can lead to decompaction of structures and slight decrease of cement materials strength at change of temperature and humidity condition of hardening.

\section{References}

[1] V. B. Ratinov, T. I. Rosenberg, Concrete admixtures, Stroyizdat, Moscow, 1989. 
[2] J. F. Young, Reaction Mechanism of Organic Admixtures with Hydrating Cement Compaunds, Trans. Res. Rec. 564 (1974) 1-9.

[3] V. Lorprayoon, D. R. Rossington, Early Hydration of Cement Constituents with Organic Admixtures, Cem. Concr. Res. 11 (1981) 267-277.

[4] V. G. Batrakov, Modified concrete. Theory and practice, Technoproject, Moscow, 1998.

[5] V. S. Ramachandran, R. F. Feldman, M. Kollepardi and oth., Concrete admixtures, Stroyizdat, Moscow, 1988.

[6] P. G. Komokhov, Properties ettringite phase in the formation of the microstructure of concrete under thermal exposure, Proceedings LIIGT, 1978.

[7] T. V. Kuznetsova, Aluminate and sulfoalyuminatnye cements, Stroyizdat, Moscow, 1986.

[8] Z. M. Larionova, L. V. Nikitina, V. R. Garashin, The phase composition, microstructure and strength of cement stone and concrete, Stroyizdat, Moscow, 1977.

[9] H. F. Taylor, Chemistry of cements, Stroyizdat, Moscow, 1969.

[10] O. V. Tarakanov, Cement, materials, with, hydrocarbon, additives, PSUAC, Penza, 2003.

[11]O. V. Tarakanov, E. A. Belyakova, Effect of superplasticizers on the plasticity of cement and mineral pastes, Concr. Tech. 2(79) (2013) 18-20.

[12] O. V. Tarakanov, V. I. Kalashnikov, E. A. Belyakova, K. A. Steshkina, Impact assessment micro filler carbonate on the kinetics of entry of structure and composition of cement hydrate phase systems, Reg. Archit. Eng. 2 (2014) 40-46. 